\title{
Seeking Clarity and Confidence in the Divorce Decision-Making Process
}

\author{
Authors: Steven M. Harris, Sarah A. Crabtree, \\ Natasha K. Bell, Sarah M. Allen, and Kelly M. Roberts
}

This is an Accepted Manuscript of an article published in Journal of Divorce \& Remarriage on March 2017, available online:

http://www.tandfonline.com/10.1080/10502556.2016.1268015.

Harris, Steven M. , Sarah A. Crabtree, Natasha K. Bell, Sarah M. Allen, and Kelly M. Roberts. "Seeking Clarity and Confidence in the Divorce Decision-Making Process." Journal of Divorce \& Remarriage 58, no. 2 (March 2017): 83-95. DOI: 10.1080/10502556.2016.1268015.

Made available through Montana State University's ScholarWorks scholarworks. montana.edu 


\title{
Seeking Clarity and Confidence in the Divorce Decision-Making Process
}

\author{
Steven M. Harris ${ }^{a}$, Sarah A. Crabtree ${ }^{a}$, Natasha K. Bella, Sarah M. Allen ${ }^{b}$, \\ and Kelly M. Roberts ${ }^{c}$
}

\begin{abstract}
aDepartment of Family Social Science, University of Minnesota Twin Cities, Minneapolis-St. Paul, Minnesota, USA; 'bepartment of Health and Human Development, Montana State University, Bozeman, Montana, USA; 'Department of Educational Psychology, University of North Texas, Denton, Texas, USA
\end{abstract}

\begin{abstract}
There is a well-established literature dedicated to why couples divorce, transitions associated with divorce, and the impact of divorce on families. However, little is known about the divorce decision-making process. We conducted in-depth interviews with individuals who have recently considered divorce ( $n=30$ ) and asked specifically about the roles of 2 concepts in their decision-making process: clarity and confidence. Three major themes emerged from the data: (a) Clarity about a decision to divorce or stay married is desired, it fluctuates, and takes time to find; (b) pivotal moments can bring clarity; and (c) confidence (in the final decision) is desired. Clinical implications and directions for future research are discussed.
\end{abstract}

\section{KEYWORDS}

Clarity; confidence; decision making; divorce

Divorce occurs to approximately $50 \%$ of all first marriages and over $65 \%$ of all second and subsequent marriages (Amato, 2000). Whereas the existing research is plentiful on the causes and outcomes of divorce, less is known about the actual decision-making process associated with divorce. This article focuses on the concepts of clarity and confidence and the role they might play in the divorce decision-making process. As clinicians, we have witnessed firsthand a lack of clarity on the part of those in the midst of this process, and those who make a decision about the future of their marriage express a desire to be confident in the choice they have made. Further, a new clinical model designed to engage couples on the brink of divorce has the goal of helping these couples achieve greater "clarity and confidence" in their decision making about the future of their marriage (Doherty, Harris, \& Wilde, 2015). Therefore, it is important to know if people in the divorce decisionmaking process value or would benefit from clarity and confidence in this process. Although there could be other factors that influence this decisionmaking process, we are especially interested in these concepts as understood 
by those who are the potential initiators of divorce. We review the current literature on the landscape of divorce decision making and make a case for the need to understand these two concepts better. Finally, we report the results of a qualitative study of people who are considering divorce and discuss their perspectives on the roles of clarity and confidence in the divorce decision-making process.

The increase in divorce in the 20th century has been said to be one of most dramatic and impactful changes to family life (Amato, 2000). Divorce is a life-altering decision for all involved and the consequences of divorce follow a person throughout his or her life (Doherty, Willoughby, \& Peterson, 2011). A great deal of research examines what causes divorce and the impact of divorce on society, families, and individuals, but we have little understanding of the process of deciding whether to stay married or to divorce, how individuals and couples make that decision, and what they experience through the decision-making process (Fackrell, 2012).

Deciding to divorce is rarely easy, and many people struggle for a great deal of time before moving in one direction or another (Fackrell, 2012). Hawkins and colleagues (2015) asked a representative sample of married individuals in the United States about their thoughts of divorce and discovered that as many as $25 \%$ of married people had thought about divorce as an option to resolve marital problems in the past 6 months, and more than half of those surveyed had thought about divorce at some point in their marriage (Hawkins et al., 2015). The researchers labeled this phenomenon of what people are "thinking about and doing when they have thoughts about divorce" as "divorce ideation" (Hawkins et al., 2015, p. 1). These finding suggest that divorce ideation is relatively common; many people consider or have considered divorce at some point in their marriage. This same study provided data that $43 \%$ of those who had recently considered divorce did not necessarily want to divorce and reported being willing to work to improve their marriage, with an additional 23\% indicating they would consider reconciliation if their spouse was willing to make major changes. Additionally, $88 \%$ of those who had considered divorce in the past but chose to stay married were glad they did and reported currently being happy in their marriage (Hawkins et al., 2015). Other findings indicate that among a group of divorcing parents mandated to attend coparenting (predivorce approval) education, in about $45 \%$ of the couples, one or both partners expressed hope for their marriage and a degree of interest in reconciliation (Doherty et al., 2011).

Ending a marriage is a big decision with significant ramifications for all involved, especially given that most people who marry originally intended their union to last "until death." Many of those in the midst of this decision-making process struggle to make the "right" decision. In interviews with women who were contemplating divorce yet chose to stay 
married, participants described the process as a roller coaster ride, a gradual process that at times was complicated, filled with ups and downs, or like having recurring intrusive thoughts to hurt oneself but without any real plan of action (Kanewischer \& Harris, 2014). This experience has also been compared to "wandering in the wilderness" where there are no clear directions or pathways (Fackrell, 2012, p. 27). The process of deciding to divorce or reconcile one's marriage tends to be confusing and dynamic, with many pushes and pulls influenced by comparisons of unknown future states. The process can be nonlinear and sometimes illogical (Fackrell, 2012).

Owen, Rhoades, et al. (2014) published a series of articles introducing the concept of commitment uncertainty. They defined it "as a metacognitive process about several facets of dedication and constraint commitment ... [that] likely includes vacillation in thoughts, emotions, and behaviors over time" (p. 209). Commitment uncertainty refers to a person's feelings of ambivalence in their current relationship (Quirk et al., 2016). The authors explained that most often couples' experiences of uncertainty about their relationship mark a change or strain in the relationship that could lead to partners experiencing "a shift in the ways they view we-ness or a shared sense of identity with their partner" (Owen, Rhoades, et al., 2014, p. 209). Those with high levels of commitment uncertainty might engage in exploring alternatives to their current relationship, including dissolution. The exploring might be fairly benign initially, but could change as a means of slowly ending the relationship (Quirk et al., 2016).

The effectiveness and impact of therapeutic interventions with commitment uncertain couples varies (Luebcke et al., 2014). Due to this variation in effectiveness of interventions, the authors suggest that it might be helpful to not only assess each partner's commitment uncertainty at the beginning of couple therapy, but also throughout the therapy process as each partner's levels of uncertainty can change (Owen et al., 2014a; 2014b). The authors further suggested that "commitment uncertainty should likely be considered as a potential mechanism of change and as a target of intervention for many couples" (Owen, Keller, et al., 2014, p. 237). Similarly, Doherty and his colleagues with the Minnesota Couples on the Brink Project at the University of Minnesota developed a therapeutic protocol called discernment counseling (Doherty et al., 2015) to assist couples with commitment uncertainty, or what he called "mixed agenda" couples, to determine an appropriate direction for their relationship. The main goals of this approach are to help the couple achieve greater clarity and confidence in making a decision about the future of their marriage based on a more complex understanding of how divorce came to be a real possibility for the marriage and each person's role in getting the marriage to the brink of divorce (for more information on discernment counseling, see Doherty et al., 2015). 
Deciding whether to divorce or stay married in the event of marital discord is an arduous process. People often consider the impact of their decision on children, their finances, their own and others' levels of happiness, and sometimes even their self-image. Competing agendas can complicate this decision-making process (e.g., weighing a desire for personal happiness against the happiness of others), and timing is often critical to whether a decision to divorce is made. This process can often feel convoluted and unclear (Hawkins et al., 2015). For this study, we examined the roles of clarity and confidence in the divorce decision-making process. The guiding question for this study was this: When a marriage is in trouble, what are the roles of clarity and confidence in the process of making a decision about the future of the marriage? Clarity is conceptualized as a quality of being clear (free from ambiguity) about whether to divorce or stay in the marriage, and confidence refers to the level of confidence a person has regarding whether or not the decision was the "right" or "best" one.

\section{Method}

\section{Sample}

Our sample was derived from the National Divorce Decision-Making Project's (NDDMP) Wave 1 survey respondent pool $(N=3,000)$, which is representative of persons in the United States, ages 25 to 50, who have been married at least 1 year. The online survey, administered in February 2015, presented a set of questions about divorce ideation and attitudes toward marriage and divorce. Analysis of the survey data revealed that one in four participants indicated they had thoughts about divorce in the past 6 months $(n=745)$. We chose to interview those who met the following inclusion criteria: had thoughts about divorce in the last 6 months, had a child or children under 18 living in the household, and were willing to be interviewed. Eligible participants were stratified over scales measuring (a) level of frequency of divorce ideation, (b) divorce attitude, (c) level of relationship hope, (d) time spent thinking about divorce, and (e) gender so a broad range of people in the midst of divorce ideation would be represented.

The final sample of interviewees $(n=30)$ consisted of 11 men and 19 women. On average, the participants were 40.8 years old, had been married for 13.5 years, and had 1.93 children under 18 years of age living in their home. Seventy-seven percent of the participants were in their first marriages, and $23 \%$ were remarried. Participants' annual incomes were less than $\$ 40,000$ (37\%), between $\$ 41,000$ and $\$ 80,000(17 \%)$, and over $\$ 80,000(43 \%)$. The participants reported being White $(n=22)$, Black $(n=3)$, Hispanic or Latino $(n=2)$, multiracial $(n=1)$, and other $(n=2)$. The majority of the participants had some higher education (52\%), whereas others were college 
graduates (35\%) or had a high school degree or less (13\%). The participants' attitudes about divorce varied. The majority reported not wanting a divorce (50\%), but $10 \%$ reported that they were done with their marriage, $17 \%$ had mixed feelings about divorce, $13 \%$ reported that they would consider staying if their spouse got serious about making changes, and 10\% reported other attitudes about divorce.

\section{Research instrument and interview procedures}

The semistructured interview was first piloted on individuals who matched the sample demographics to test the content, ordering of questions, and its duration. The final interview schedule was comprised of 12 questions and took approximately $45 \mathrm{~min}$ to $1 \mathrm{hr}$ to complete. The interview explored several dimensions of the divorce decision-making process, including context, meaning and sense-making, decision-making processes, moments of clarity and confidence, feelings of being stuck, identity, love, happiness, reconciliation, and the degree(s) to which their decision making was public or private. All interviews ended with a question exploring a creative metaphor to describe the decision-making process and a request to explore anything further that had been missed in the interview.

The interviews were conducted by telephone and were audio-recorded and later transcribed. Researchers at three universities split the interviewing responsibilities, and eligible interviewees were contacted on a rolling basis until 30 interviews were completed. Participants were compensated with a $\$ 75$ gift card.

\section{Analysis}

Analysis of the interviews followed principles of general qualitative thematic analysis (Braun \& Clarke, 2006), involving becoming familiar with the data by reading the transcripts; generating initial open codes; solidifying a codebook; examining, defining, and naming overarching themes; and creating a theoretical story. Elements of Glaser and Strauss's (1967) coding protocol for grounded theory were also incorporated into the analysis, such as memo writing and open, axial, and selective coding. Before data were collected, the full research team attended a multicoding and analysis training as a way to create consensus in the coding approach across sites. Because the 30 interviews were split among three research sites, the initial reviews of the transcripts and open coding were a collaborative effort. First, the lead researcher at each site and the on-site research team, including one or two graduate or undergraduate students, joint-coded every interview conducted at their site. This was done to cast a wider analytic net, establish intercoder agreement, and remain consistent with the assignment of particular codes to the data. Principal coders from all of the research teams met weekly to discuss 
terminology, themes, and categories to build consensus as new discoveries emerged. This helped ensure that the coding process was harmonious across research sites. From these weekly meetings a codebook was derived, which reflected the shared interpretation and understanding of the phenomenon being studied. After each team had coded their respective interviews, they also coded five uncoded interviews from each of the other teams and then compared their coding scheme with what the original team had coded. This was done to further establish intercoder agreement and build interpretive convergence across the interviews.

This study focused on the concepts of clarity and confidence as they pertain to the divorce decision-making process. We were specifically interested in understanding more about the role of these concepts in the lives of the spouse who was the potential initiator of a divorce, or who was actively thinking about initiating a departure from or change in the marital status. Although divorce ideation was something all interviewees were experiencing, the majority of our participants were thinking about divorce because of their own dissatisfaction in the marriage, and not merely because their spouse was the one initiating it.

All respondents were asked the same question: "Have you experienced moments during this process where you felt you've had clarity or confidence about a particular decision?" The following probing questions were included in some of the interviews to enhance the description of the original response: "What helped you experience that kind of clarity or confidence? How clear are you about this decision (to stay married/get divorced)? How confident are you with this decision?"

\section{Results}

The analysis of the concepts of clarity and confidence in divorce decision making resulted in three primary themes: (a) clarity about a decision to divorce or stay married is desired, it fluctuates, and it takes time to find; (b) pivotal moments can bring clarity (to their decision-making process); and (c) confidence (in the final decision) is desired. These themes are presented in the order of salience in the participants' narratives.

\section{Clarity is desired, it fluctuates, and it takes time to find}

This theme was the most prominent, and it represents the fluid nature of how participants consider the future of their marriage, including factors that make clarity about a decision to divorce or stay married difficult to find. Half of those interviewed reported in the initial survey that they did not want a divorce, but these same participants had also indicated that they had thought about divorce in the previous 6 months. These data, along with the 
participants' narratives about their decision making, suggested that finding clarity about how to clearly conceptualize the future of the marriage when thoughts of divorce emerge is challenging.

In describing whether to divorce or stay married, one participant said, "It changes week to week." The seriousness of a decision to divorce seemed to weigh on participants in such a way that it made the decision-making process slow. One participant said, "I really don't have clarity in the situation because, I just don't ... I just don't make decisions on anything that quickly, I just like to process for a long time" (30-year-old mother of one, married for 9 years). Similarly, participants acknowledged that a decision to remain married was not necessarily equivalent to a decision to divorce, as deciding to stay married now does not necessarily mean they will decide this in the future. One participant talked about it this way: "Well, I am definitely more positive about it than I was a few months ago, but I'm still a little bit reserved about the long-term possibilities of us staying together, but I think at least in the short term it's looking pretty good (staying married)" (48-year-old mother of three, married for 16 years).

A common experience among participants that led to the difficulty in finding clarity was the recognition that their marriage was not all bad. Despite marital strain and thoughts of leaving, there were positive elements to their marriages that muddied their decision-making processes. For example, one woman was ready to leave her marriage, but her clarity was shaken by her husband's response:

When I said to him I was ready to walk away, and he realized that I'd [be willing to] check into a homeless shelter with the children [to get out], he was like, "I would never, ever make you go through that. If you want to be separated, I would sleep in the car outside ... If you wanted me to sleep in the living room I would ... you wouldn't have to do anything until you can find your own car, find your own place." And it was just like, "Whoa, we're sitting here arguing and he's still going to make sure that I'm taken care of." (25-year-old mother of two, married 1 year)

Another woman provided a fairly poignant summary of her thoughts on the role of clarity in her decision making and the time it takes to arrive at clarity:

[Divorce] doesn't happen in a moment, you know, or in a day. I think it happens over a period of time. I think people ... think about it for a while. When I make my decision, it will be final and decisive. But it sure does take me thinking about all the different things ... like should I go down this road? ... Then what? What will my life look like, what will it be? And then I try to think about it long enough where my emotions stop being in play because I can't turn them off especially when we're fresh off a fight. It affects how I think about things. So 2, 3 days later, the fight is over and if my emotions aren't so raw and I can think about things more clearly and more precisely and more rationally, so then I feel like I made a better decision. Because you can't make decisions when you're afraid, when you're tired, when you're, you know, just frustrated. No decisions made off of those positions are 
good decisions. There's no way because you haven't thought everything through because you're clouded by that fear, that frustration, that feeling of I'm just sick and tired of everything. I try not to make decisions when I'm in those states so when I get clearer, then I feel like I make a better decision or the decision is better and if divorce comes from that clarity, then it does. But either way, I don't think it's instant. (31-year-old mother of two, married 8 years)

Other participants acknowledged they had clarity about wanting to leave the marriage, but a lack of clarity about specific elements of the future that rendered making a decision to leave difficult. A 47-year-old father of two, married for 13 years, said, "If I was confident that I had an opportunity to keep custody of my kids I wouldn't be waiting." Others connected their lack of clarity to their concerns for the impact a divorce would have on their children or their financial situations. Some indicated that clarity about a decision to divorce was elusive and the idea of staying married was always present. "There's never been a moment, during the whole time that I've ever felt like, 'Okay, I'm leaving, I'm done.' I never, never completely threw the towel in" (43-year-old mother of three, married for 16 years).

Most of the respondents indicated that arriving at clarity takes time and really cannot be rushed. Further, they seemed to be saying that having moments of clarity does not necessarily equal being totally and finally clear. Sometimes clarity would come at different moments but it would be fleeting.

I would say ... the fuzziness comes in times of the waning relationship. There are moments when you think you may be thinking clearly when you're thinking about leaving and then as time goes by, you kind of reassess that thought and you may have not been thinking too clearly. When I'm stuck and I don't think I'm thinking very clearly my process is always to sit down and wait and not do anything in a rash matter and see if that cloudiness passes and I can think clearly about it later on. (48-year-old father of two, married for 16 years)

Clarity of thought seems to be a desirable trait in the divorce decisionmaking process. However, it can be elusive and take some time to find.

\section{Pivotal moments can bring clarity}

This second theme represents moments, events, and circumstances that helped participants find that clarity, leading them to more strongly consider either leaving or staying, if even for the time being. Interestingly, these moments seemed to, more often, motivate the participants to decide to stay married. Also, these moments seemed to be most often related to something their spouse did. In response to a question about a time she felt clear about wanting to stay in or leave the marriage, a woman married for 12 years with three children said: 
I guess the time he told me ... he was leaving, is when reality really hit. After he was gone and a few days, I was like, "He's not coming back," I really started thinking ... it really started to sink in. And then as time [went] on it really started to sink in that this is the person I want, this is the person that I do want to be with, that I said I was going to be with. That's when I decided I wanted to change things and be able to work them out.

Another woman said, "He reminded me of the marriage vows we took. For better or for worse, in rich or in poor, in sickness and in health ... it made me put my marriage into perspective."

All of the participants were in a decision-making phase after having reported recent thoughts of divorce, and although some were leaning toward divorce, none of them reported a clear intent to leave the marriage at the time of the interviews. However, several times participants imagined circumstances that they felt certain would convince them to leave. The most salient of these circumstances was physical violence, which was referred to in several of the interviews. One participant said, "If he ever put his hands on me, then my decision is made" (43-year-old mother of two, married 19 years). These participants were referring to a hypothetical threshold at which their tolerance for what was not working in the marriage would be gone, and their decision to leave would be clear.

Others highlighted more mundane aspects of married life that they would reflect on while in the midst of their divorce decision making and that these became pivotal moments that helped them in their decision making. One participant referred to times when she and her husband would "talk about the future or we're just spending time together and really getting along. That's a moment of clarity" (39-year-old mother of four, married for 5 years).

\section{Confidence is desired: "I want to know I made the right decision"}

The final major theme represented in the participants' narratives refers to their desire to be confident in the decision they make. Participants shared a variety of reasons for this desire, including fear of regret, personal integrity, and the sake of their children. This was especially true for decisions to divorce, as this decision was less reversible than a decision to stay married. A 48-year-old mother of three, married for 16 years, succinctly talked about her desire for confidence this way:

I wanna feel like I made the right decision. So I don't wanna say "Oh, I'm getting a divorce" and then a year into it I think, "Wow, I really wish I hadn't done that." Or, vice versa I suppose. I suppose it's not quite the same when you flip flop it because then there's always still that option of leaving if you decide to stay. When I get older I don't wanna look back on it and feel like I wasted time either way. Wasted time in an unhappy marriage or wasted time going through a divorce when it would be horrible, hard, difficult on everybody only to realize you know, at 
the end of the day maybe that really wasn't the right thing. I don't wanna be unhappy about that decision.

Another man (47-year-old father of one, married for 20 years) felt especially convicted about the necessity of confidence because of his own parents' divorce and the ways he knows his son would be affected if he chose to leave his marriage: "My litmus test is [that] I've got to be able to look [my son] in the eye and have the same level of integrity that I've always had, because that's important for me for him to grow up that way. Y'know, I had to overcome the choices that my mother made and I don't want to do that to my son." Another indicated that he did not like making the wrong decision and that he'd be willing to postpone a decision for some time just to ensure it was the right one: "I don't like to make the wrong decisions so I'll keep that decision in the back of my mind and see if it changes with my thoughts" (48year-old father of two, married for 16 years).

Some participants leaned toward leaving the marriage, but they felt confident that staying was the best choice, at least for the time being. This was most often because of the financial implications of divorce and the impact it might have on their children. For example, one participant (45-year-old father of two, married for 19 years) indicated that, "A lot [of my decision to stay] surrounds money and what's best for the kids." Finally, one participant (43-year-old mother of five, married for 22 years) seemed to sum up the desire for confidence and explained her process for arriving at it:

The confidence, that's the part that I'm still working on. Because it's easy to believe everything will work out and that I'm doing the morally right thing [by staying married] when we're not disagreeing. But as soon as something happens that reminds me of our history ... you know, I feel worried, I feel scared, I second guess ... so the confidence isn't always there. I feel like the periods of confidence now outweigh the periods of doubt and worry. But it's still pretty close, it's not that far from $50 / 50$. Maybe like $60 \%$ confidence ... well maybe $70 \%$ confidence, but still $30 \%$ of ... Are we going to be able to make this work?

Like arriving at a place of clarity in a decision to stay married or divorce, feeling confident in the final decision regarding the future of one's marriage is desired. People want to know they are making the right and best decision when it comes to staying married or pursuing a divorce.

\section{Discussion}

The results of this study support what we, as clinicians who work with couples on the brink of divorce, have witnessed and can attest to anecdotally: Clarity and confidence in the divorce decision-making process are desired, yet are ever elusive. These findings challenge assumptions that arriving at a decision to divorce is a linear process and add to the growing body of 
research that suggests the divorce decision-making process can be marked with confusion and ambivalence (Doherty et al., 2011; Fackrell, 2012) There are several implications of these findings for clinical work. First, practitioners and educators who work with this population might be encouraged to normalize both the desire for and the elusive nature of clarity and confidence in the divorce decision-making process. For those struggling to find clarity and confidence in this decision-making process, it might come as a bit of a relief to know that most people in a similar situation are looking for these very things as part of their process, too. Our participants seemed to be saying that clarity and confidence are desired but that they both take some time to arrive at and that making a decision about the future of one's marriage might even ultimately pass through moments of clarity that are fleeting.

One mistake marital therapists can make with couples in this process is encouraging them to prematurely make a decision about the future of their marriage instead of allowing them to "sit with" their ambivalence and not rush to a decision one way or the other. Most therapeutic models hinge on the assumption that both spouses come to therapy hoping to improve their relationship (Doherty et al., 2015). As a result, therapy with couples who feel rushed to make a decision to work on their marriage is likely to be ineffective. Similarly, therapists might be inclined to discontinue treatment if one spouse indicates a desire to divorce. One of the clinical implications of this study might be the importance of making the achievement of clarity and confidence in a decision about the future of one's marriage or relationship the main treatment goal for couple or individual therapy. Doherty et al. (2015) promoted an approach that does this very thing. Discernment counseling is a unique clinical approach for couples facing the possibility of divorce where one spouse is either ambivalent or leaning out of the marriage and the other partner is leaning into, or is desirous to strengthen the marriage. It is not uncommon that couples might present to therapy in this very manner, and Doherty and colleagues (2011) suggested that up to $30 \%$ of all couples that attend marital therapy might present with mixed agendas.

\section{Limitations}

This study is not without limitations. As an initial study designed to get at the heart of the concepts of clarity and confidence and the role they might play in divorce decision making, we only interviewed 30 people. We cannot say with confidence that everyone facing a divorce decision will be desiring or even lacking these concepts in their process, but this gives a good place to start other scholarship around these concepts. Without random sampling, the results from this study cannot generalize beyond the group we interviewed. However, we take heart in the fact that the original sample from 
which our 30 interviewees were selected was a fairly representative sample of married people in the United States between the ages of 25 and 50.

There are several ways this literature could be expanded. Future research could examine the extent to which feeling clear and confident about a decision to divorce or stay married predicts the actual decision made. Additionally, factors that make clarity and confidence especially difficult to find should be explored in greater depth. Finally, larger and more diverse samples could lead to greater understanding about divorce ideation across different populations of married persons.

\section{Summary}

We used a qualitative design to explore the concepts of clarity and confidence in the divorce decision-making process with 30 participants who reported recent thoughts about divorce. The participants' narratives suggest that clarity about a decision to divorce or stay married, and feeling confident in that decision, are desirable but often elusive elements of the divorce decisionmaking process. Although these findings are not generalizable to the entire population of married persons considering divorce, these findings might be useful for practitioners and educators who work with couples on the brink of divorce. These professionals could normalize the absence of clarity and confidence for their clients and might benefit from adjusting therapeutic approaches to more effectively work with ambivalence about a decision to divorce or stay married.

\section{Funding}

The authors are grateful to the Brigham Young University School of Family Life for their financial support of this project.

\section{References}

Amato, P. R. (2000). The consequences of divorce for adults and children. Journal of Marriage and Family, 62, 1269-1287. doi:10.1111/j.1741-3737.2000.01269.x

Braun, V., \& Clarke, V. (2006). Using thematic analysis in psychology. Qualitative Research in Psychology, 3(2), 77-101. doi:10.1191/1478088706qp063oa

Doherty, W. J., Harris, S. M., \& Wilde, J. L. (2015). Discernment counseling for "mixed agenda" couples. Journal of Marital and Family Therapy, 42, 246-255. doi:10.1111/ jmft.12132

Doherty, W. J., Willoughby, B. J., \& Peterson, B. (2011). Interest in marital reconciliation among divorcing parents. Family Court Review, 49, 313-321. doi:10.1111/j.17441617.2011.01373.x

Fackrell, T. A. (2012). Wandering in the wilderness: A grounded theory study of the divorce or reconciliation decision-making process (Doctoral dissertation). Retrieved from ProQuest Dissertations \& Theses: Gradworks. (3506127) 
Glaser, B., \& Strauss, A. (1967). The discovery of grounded theory. London, UK: Weidenfeld \& Nicholson.

Hawkins, A. J., Roberts, K. M., Harris, S. M., Allen, S. M., Schramm, D., Galovan, A., \& The National Divorce Decision-Making Project. (2015). What are they thinking? A national survey of married individuals who are thinking about divorce. Provo, UT: Family Studies Center, Brigham Young University. Retrieved from https:/familycenter.byu.edu/ Documents/What\%20are\%20they\%20thinking\%20FINAL\%20digital.pdf

Kanewischer, E. J. W., \& Harris, S. M. (2014). Deciding not to un-do the "I do": Therapy experiences of women who consider divorce but decide to remain married. Journal of Marital and Family Therapy, 41, 367-380. doi:10.1111/jmft.12064

Luebcke, B., Owen, J., Keller, B., Shuck, B., Knopp, K., \& Rhoades, G. K. (2014). Therapy interventions for couples: A commitment uncertainty comparison. Couple and Family Psychology: Research and Practice, 3, 239-254. doi:10.1037/cfp0000031

Owen, J., Keller, B., Shuck, B., Luebcke, B., Knopp, K., \& Rhoades, G. K. (2014a). An initial examination of commitment uncertainty in couple therapy. Couple and Family Psychology: Research and Practice, 3, 232-238. doi:10.1037/cfp0000030

Owen, J., Rhoades, G., Shuck, B., Fincham, F. D., Stanley, S., Markman, H., \& Knopp, K. (2014b). Commitment uncertainty: A theoretical overview. Couple and Family Psychology: Research and Practice, 3, 207-219. doi:10.1037/cfp0000028

Quirk, K., Owen, J., Shuck, B., Fincham, F. D., Knopp, K., \& Rhoades, G. (2016). Breaking bad: Commitment uncertainty, alternative monitoring, and relationship termination in young adults. Journal of Couple \& Relationship Therapy, 15, 61-74. doi:10.1080/ 15332691.2014.975306 